\section{(2) OPEN ACCESS}

\title{
Erector spinae catheter for post-thoracotomy pain control in a premature neonate
}

\author{
Anna Swenson Schalkwyk, ${ }^{1}$ James Flaherty, ${ }^{1}$ Donavon Hess, ${ }^{2}$ Balazs Horvath (D) ${ }^{1}$
}

${ }^{1}$ Anesthesiology, University of Minnesota, Minneapolis, Minnesota, USA 2Department of Surgery, University of Minnesota, Minneapolis, Minnesota, USA

Correspondence to Dr Balazs Horvath; bhorvath@umn.edu

Accepted 29 July 2020
Check for updates

(c) BMJ Publishing Group Limited 2020. Re-use permitted under CC BY-NC. No commercial re-use. See rights and permissions. Published by BMJ.

\section{To cite:}

Swenson Schalkwyk $A_{\text {, }}$

Flaherty J, Hess D, et al. BMJ Case Rep 2020;13:e234480. doi:10.1136/bcr-2020-

234480

\begin{abstract}
SUMMARY
Ensuring respiratory stability with early tracheal extubation and adequate pain control is challenging in premature neonates after thoracotomy. Continuous erector spinae plane (ESP) block, a relatively new truncal nerve block, has the potential to provide analgesia for thoracic surgeries while reducing opioid use. However, there have been only a few reports utilising this technique in infants, and none in preterm neonates. We present the perioperative pain management of a preterm neonate requiring thoracotomy. Epidural analgesia was deemed contraindicated due to coexisting coagulopathy; therefore, an ESP catheter was placed. The patient was extubated at the end of the surgery and had excellent pain control with rectal acetaminophen, chloroprocaine infusion via the ESP catheter and with minimal opioid requirement. Continuous ESP block may be safe and effective for postoperative pain management in coagulopathic premature neonates. Chloroprocaine is an effective local anaesthetic in the erector spinae compartment, which has not been previously reported.
\end{abstract}

\section{BACKGROUND}

Pain management after thoracotomy is challenging in premature neonates. Regional anaesthesia can be a useful adjunct to reduce opioid-related respiratory depression, but many of these patients present with contraindications to the traditional standard epidural analgesia. The erector spinae plane (ESP) block has emerged as a potential analgesic option in this patient population. The ESP block provides analgesia by indirectly targeting both the dorsal and the ventral rami of multiple levels of spinal nerves through deposition of local anaesthetic deep to the erector spinae muscle. ${ }^{1}$ The potential advantage of this indirect approach is that bleeding complications associated with this block are likely to be less consequential compared with epidural blockade due to the relatively superficial and readily compressible location of needle placement. Though little data is available to compare the analgesia from ESP blocks with epidurals, there is growing evidence of analgesic effectiveness of the ESP block for acute and chronic thoracic pain. Continuous ESP blocks have been used as an analgesic adjunct in adult and older paediatric thoracotomy patients. ${ }^{2-4}$

Only single injection ESP blocks, which provide analgesia of limited duration, have been reported in preterm neonates that presented for thoracic surgery. ${ }^{5-8} \mathrm{~A}$ continuous block is desirable for these patients to allow the provision of several days of opioid-sparing analgesia. However, continuous ESP blocks may require large volume local anaesthetic infusions to be efficacious, which presents an additional challenge in this population due to immature hepatic metabolism and increased susceptibility to the cardiotoxic and neurotoxic effect of aminoamide local anaesthetics. ${ }^{9}$

We present the novel management of a coagulopathic premature neonate undergoing thoracotomy for tracheoesophageal fistula (TEF) repair with a preoperatively placed ESP catheter with continuous intraoperative and postoperative chloroprocaine infusion.

\section{CASE PRESENTATION}

Informed consent was given by the patient's parent to publish this report.

A 2-day-old, $2.25 \mathrm{~kg}$ female infant, born at 35 weeks 6 days, presented for TEF repair via right thoracotomy. Workup for associated anomalies found a bifid S4 vertebral segment, aberrant right subclavian artery and possible anorectal anomaly. Laboratory tests were notable for unexplained coagulopathy with international normalised ratio (INR) 2.6, despite routine vitamin $\mathrm{K}$ administration intramuscularly 1 hour after birth. The patient's INR remained elevated at 1.6 on the morning of surgery despite fresh frozen plasma administration.

\section{TREATMENT}

We viewed the patients elevated INR as a contraindication to epidural placement, as per The American Society of Regional Anesthesia and Pain Medicine (ASRA) guidelines. ${ }^{10}$ Therefore, a continuous ESP block was planned. Following uneventful anaesthesia induction and rigid bronchoscopy, the trachea was intubated and the patient was turned to the left lateral decubitus position. At the level of the marked planned T7-8 chest tube site, we identified a parasagittal view of the right erector spinae muscle group and thoracic transverse processes with ultrasound. Following sterile preparation, we advanced a 20-gauge Tuohy needle in plane from caudal to cephalad deep to the erector spinae muscle at T7-8 (figure 1A). We aimed to place the catheter tip at the midpoint (T5-6) between the planned T4-T5 incision and T7-8 chest tube sites to achieve sufficient cephalad and caudal spread of the local anaesthetic solution to provide analgesia at both sites of source of postoperative pain. ${ }^{11}$ We injected $1.5 \mathrm{~mL}$ normal saline to open the ESP and threaded a 24-gauge epidural catheter into the plane. Catheter location 

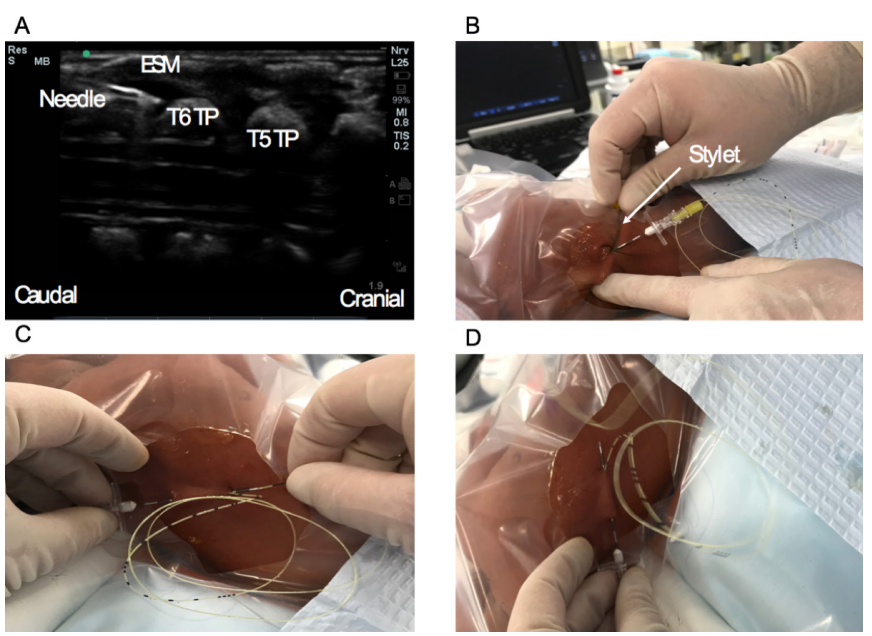

Figure 1 (A) Ultrasound image of the needle in the erector spinae muscle plane. (B-D) Tunnelling the catheter away from the surgical field by using the 20-gauge Tuohy needle and stylet to create a subcutaneous conduit for the catheter. ESM, erector spinae muscle; T6TP, thoracic 6 transversus process; T5TP, thoracic 5 transversus process.

was confirmed with $0.5 \mathrm{~mL}$ normal saline and $2 \mathrm{~mL} 3 \%$ chloroprocaine. The catheter was tunnelled away from the planned surgical site (figure $1 \mathrm{~B}-\mathrm{D}$ ) and secured with a sterile dressing. A posterolateral thoracotomy incision was made and the chest wall was opened between the fourth and fifth ribs. We chose $1.5 \%$ chloroprocaine for local anaesthetic solution; however, it was not readily available from our pharmacy to administer a loading bolus dose. While awaiting chloroprocaine infusion preparation, $1 \mathrm{~mL} 0.1 \%(0.44 \mathrm{mg} / \mathrm{kg})$ ropivacaine bolus was administered prior to incision. One hour later, an infusion of $1.5 \%$ chloroprocaine was initiated at $0.25 \mathrm{~mL} / \mathrm{kg} /$ hour $(3.75 \mathrm{mg} / \mathrm{kg} /$ hour $)$. We took care to ensure that the administered doses were significantly lower than the maximum allowed doses for each local anaesthetics individually and in their current combination. The patient received remifentanil $0.1 \mathrm{mcg} / \mathrm{kg} / \mathrm{min}$ during the first half of the case, but no other intraoperative opioids. Following chest tube placement between the seventh and the eighth ribs and completion of the surgery, the patient was extubated and transferred to the neonatal intensive care unit.

\section{OUTCOME AND FOLLOW-UP}

Postoperative analgesia was supplied via chloroprocaine infusion and scheduled rectal acetaminophen. The Neonatal Pain, Agitation and Sedation Scale (N-PASS) was recorded every 2 hours to assess postoperative pain. Our patient received two doses of morphine $(0.05 \mathrm{mg} / \mathrm{kg}$ per dose $)$ on each of the postoperative days (POD) 1 and 2 for N-PASS scores of 5-7. The remainder of N-PASS scores was recorded as 0-2. Oxygen supplementation via nasal cannula was titrated off POD 2. The erector spinae catheter was removed without complication on POD 5. A repeat INR was 1.17 prior to catheter removal, and there were no signs of impaired haemostasis. The patient was discharged home on POD 8. No short-term or long-term complications related to the ESP block were observed.

\section{DISCUSSION}

This case suggests that continuous erector spinae blocks may have a role in managing perioperative pain in premature neonates undergoing thoracotomy, similar to the few published case reports in older infants. ${ }^{3}$ Pain management following thoracotomy is especially challenging in premature neonates. Uncontrolled pain generates a pattern of rapid shallow breathing, which predisposes to atelectasis. Conversely, opioid use in this population may contribute to respiratory complications. For example, respiratory depression requiring noninvasive positive pressure ventilation or reintubation can stress delicate suture lines. ${ }^{12}$ Opioid-sparing regional anaesthesia may be the ideal solution, but approaches are often contraindicated in these patients by comorbid conditions of prematurity. With continuous ESP block, our patient had low postoperative pain scores and minimal need for supplemental opioids.

Our patient had both coagulopathy, INR 1.6 and sacral anatomic abnormalities as relative contraindications to caudal epidural catheter placement. An INR greater than 1.2 is considered a contraindication to neuraxial needle placement by the guidelines issued by ASRA. ${ }^{10}$ The European Society of Anaesthesiology (ESA) considers an INR of 1.4 as the cut-off for neuraxial procedures. ${ }^{13}$ Moreover, ASRA advises against performing paraneuraxial blocks, such as paravertebral blocks, in coagulopathic patients due to the inability to compress those compartments should bleeding occur. ${ }^{10}$ While the bleeding risk associated with ESP catheter placement is still being determined, the compressibility of the location and its distance from the neuraxis may reduce bleeding risk compared with epidural placement. This unknown bleeding risk must be carefully weighed in a coagulopathic patient as an unrecognised bleeding event may have severe consequences. We viewed the potential analgesic and respiratory benefits to outweigh the risk of ESP catheter placement.

To our knowledge, this is the first case report of a preterm neonate undergoing thoracotomy with a continuous ESP block within the first week of life. While these patients present anatomy favourable for placement of these blocks, their management requires careful attention to detail. First, the location of catheter placement is much closer to the surgical field than that of a caudal catheter. We were able to tunnel our catheter subcutaneously across the midline to the satisfaction of our surgical team. Second, the choice of local anaesthetic and infusion method may significantly impact the success of this technique. The aminoamide local anaesthetics bupivacaine and ropivacaine are used almost universally for continuous peripheral nerve blocks, including in infants and neonates. In contrast to other published case reports of neonatal continuous ESP blocks, ${ }^{314}$ we elected to infuse $1.5 \%$ chloroprocaine postoperatively. Given the immature hepatic function in patients at this age, we believe that substituting this for the more commonly used aminoamide local anaesthetics may reduce these patients' risk of local anaesthetic toxicity. ${ }^{9}$ We chose the infusion rate as it was published in several successful paediatric ESP catheter case reports, and it is a safe rate of chloroprocaine infusion. ESP catheter placement is feasible for premature neonates, and it provides effective intraoperative and postoperative analgesia for thoracotomy. It may contribute to a strategy for early extubation and reduce pain or opioid-related respiratory depression during recovery. It is likely lower risk than neuraxial block in the setting of mildto-moderate coagulopathy, though this case report does not amount to evidence of absolute safety in these patients. Chloroprocaine may be the ideal local anaesthetic in the erector spinae compartment in neonates to allow for high-volume infusion while minimising the risk of toxicity. Although the paediatric literature comprises of mostly case reports, there are a growing number of successful applications of ESP blocks in infants and children. We are encouraged to use this technique in future cases to validate its usefulness and establish a specific dose range of 
chloroprocaine infusion. However, prospective randomised clinical trials are required to assess the effectiveness and safety of this technique compared with other, traditional perioperative analgesia methods.

In conclusion, this case is the first demonstration in our practice of the potential value of continuous ESP blocks in this difficult patient population. Our patient was extubated at the end of surgery and required minimal postoperative opioids without any obvious adverse events associated with the regional technique.

\section{Learning points}

- Erector spinae block is a feasible regional anaesthesia technique for premature neonates.

- Erector spinae plane may be a favourable substitute to conventional epidural analgesia in the setting of mild-tomoderate coagulopathy.

- Chloroprocaine may be an effective local anaesthetic option for continuous erector spinae blocks in preterm neonates.

\section{Twitter Balazs Horvath @hbali66}

Contributors ASS directed anaesthetic care for the patient and helped write and edit the manuscript and approved it for submission. JF participated in block placement and helped edit the manuscript and approved it for submission. DH performed the surgery, supervised postoperative care and helped edit the manuscript and approved it for submission. BH performed the erector spinae block and helped write and edit the manuscript and approved it for submission.

Funding The authors have not declared a specific grant for this research from any funding agency in the public, commercial or not-for-profit sectors.

Competing interests None declared.

Patient consent for publication Parental/guardian consent obtained.

Provenance and peer review Not commissioned; externally peer reviewed.

Open access This is an open access article distributed in accordance with the Creative Commons Attribution Non Commercial (CC BY-NC 4.0) license, which permits others to distribute, remix, adapt, build upon this work non-commercially, and license their derivative works on different terms, provided the original work is properly cited and the use is non-commercial. See: http://creativecommons.org/licenses/by-nc/4.0/.

\section{ORCID iD}

Balazs Horvath http://orcid.org/0000-0002-1566-6564

\section{REFERENCES}

1 Costache I, Pawa A, Abdallah FW. Paravertebral by proxy - time to redefine the paravertebral block. Anaesthesia 2018;73:1185-8.

2 Fang B, Wang Z, Huang X. Ultrasound-Guided preoperative single-dose erector spinae plane block provides comparable analgesia to thoracic paravertebral block following thoracotomy: a single center randomized controlled double-blind study. Ann Trans/ Med 2019;7:174

3 Adler AC, Yim MM, Chandrakantan A. Erector spinae plane catheter for neonatal thoracotomy: a potentially safer alternative to a thoracic epidural. Can J Anaesth 2019;66:607-8.

4 Kaplan I, Jiao Y, AuBuchon JD, et al. Continuous erector spinae plane catheter for analgesia after infant thoracotomy: a case report. A\&A Practice 2018;11:250-2.

5 Altıparmak B, Korkmaz Toker M, Uysal Ali İhsan, et al. Erector spinae plane block for pain management of esophageal atresia in a preterm neonate. $J$ Clin Anesth 2019:56:115-6.

6 Carvalho EVG, Marques JLB, Santos MJFGD. [General anesthesia combined with erector spinae plane block for ductus arteriosus closure: two case reports]. Rev Bras Anestesiol 2020;70:171-4.

7 Hernandez MA, Palazzi L, Lapalma J, et al. Erector spinae plane block for inguinal hernia repair in preterm infants. Paediatr Anaesth 2018;28:298-9.

8 Basaran B, Akkoyun I. Erector spinae plane block for management of major abdominal surgery in a low birth weight preterm neonate. J Clin Anesth 2020;61:109641.

9 Oda Y. Pharmacokinetics and systemic toxicity of local anesthetics in children. J Anesth 2016:30:547-50.

10 Horlocker TT, Vandermeuelen E, Kopp SL, et al. Regional anesthesia in the patient receiving antithrombotic or thrombolytic therapy: American Society of regional anesthesia and pain medicine evidence-based guidelines (fourth edition). Reg Anesth Pain Med 2018:43:263-309.

11 Govender S, Mohr D, Bosenberg A, et al. A cadaveric study of the erector spinae plane block in a neonatal sample. Reg Anesth Pain Med 2020:45:386-8.

12 Ferrand A, Roy SK, Faure C, et al. Postoperative noninvasive ventilation and complications in esophageal atresia-tracheoesophageal fistula. J Pediatr Surg 2019;54:945-8.

13 Gogarten W, Vandermeulen E, Van Aken $\mathrm{H}$, et al. Regional anaesthesia and antithrombotic agents: recommendations of the European Society of Anaesthesiology. Eur J Anaesthesiol 2010;27:999-1015.

14 Moore R, Kaplan I, Jiao Y, et al. The use of continuous erector spinae plane blockade for analgesia following major abdominal surgery in a one-day old neonate. J Clin Anesth 2018;49:17-18.

Copyright 2020 BMJ Publishing Group. All rights reserved. For permission to reuse any of this content visit

https://www.bmj.com/company/products-services/rights-and-licensing/permissions/

BMJ Case Report Fellows may re-use this article for personal use and teaching without any further permission.

Become a Fellow of BMJ Case Reports today and you can:

- Submit as many cases as you like

- Enjoy fast sympathetic peer review and rapid publication of accepted articles

- Access all the published articles

- Re-use any of the published material for personal use and teaching without further permission

Customer Service

If you have any further queries about your subscription, please contact our customer services team on +44 (0) 2071111105 or via email at support@bmj.com.

Visit casereports.bmj.com for more articles like this and to become a Fellow 